\title{
Application of Positive Psychology in Adaptive Education
}

\author{
Huimin Song \\ Graduate School \\ Jiangxi University of Traditional Chinese Medicine \\ Nanchang, Jiangxi, China \\ 614589688@qq.com \\ Yanru Zhang \\ Graduate School \\ Jiangxi University of Traditional Chinese Medicine \\ Nanchang, Jiangxi, China
}

\author{
Fan Gao \\ Graduate School \\ Jiangxi University of Traditional Chinese Medicine \\ Nanchang, Jiangxi, China \\ Kesui Deng* \\ School of Humanities \\ Jiangxi University of Traditional Chinese Medicine \\ Nanchang, Jiangxi, China \\ 995948023@qq.com
}

\begin{abstract}
In order to promote the development of adaptive education, firstly, this work expounded a specific case, and then analyzed the importance and existing problems of adaptive education, finally discussed how to use the advantages of positive psychology in adaptive education. Promoting the development of adaptive education has a long way to go, which requires the joint efforts of society, government, schools and families.
\end{abstract}

Keywords-positive psychology; adaptive education; people-oriented; self; the value of life

\section{INTRODUCTION}

The popular documentary "Post-00s" has attracted a lot of people's attention to education. It is the first series of documentaries in China to track the growth of post-00s children for ten consecutive years. It was produced by CCTV Documentary Channel and produced by Beijing Normal University Documentary Center. As post-00s' parents, they treat every period of their children's growth as a very important thing from birth. In order not to let their children lose at the starting line, parents urge their children to do their homework and attend various training classes. Parents hope their children achieve good results and then be admitted to key junior high schools, key senior high schools and even key universities. But as children grow up, when they reach puberty, they gradually break away from the life route designed by their parents. There seems to be a gap between parents and children, and children become what they think they are. It seems justifiable to cultivate children according to social needs and temptations, but can children's lives be designed? What exactly is education? All of these arouse our thinking.

\section{OVERVIEW OF ADAPTIVE EDUCATION AND POSITIVE PSYCHOLOGY}

\section{A. The development course and specific connotation of adaptive education}

Most people think that children's lives can be designed, because they do not have enough life experience and social experience to make the right choices for themselves, so parents and teachers should point out the way for them. Many questions such as whether the children really like it or not are beyond their consideration. Maybe the education route designed in this way has succeeded in the end, but the children have lost themselves at the same time. Now there is a saying that "hollow disease", that is, the psychological barrier caused by the defect of values, which is embodied in the feeling that life is meaningless, feeling very confused about life and not knowing what they want. Strictly speaking, "hollow disease" is not a psychological disease, but it is widespread in today's society. This phenomenon was first proposed by Xu Kaiwen, a psychologist at Peking University, in his speech "hollow disease and anxiety economics of the times" at the Ninth New Oriental Family Education Summit Forum in 2016[1]. The prevalence of "hollow disease" is closely related to the way of education.

Bruno, an American educator, once said, "The basic attitude of educators is to choose the education suitable for children, rather than the children suitable for education.” The Outline of the National Medium and Long Term Education Reform and Development Plan (2010-2020) also points out that: we should establish the concept of talent cultivation for all students and promote their growth; we should establish a diversified concept of talent, respect individual choice, encourage personality development, and cultivate talents without sticking to one pattern. This marks the first time that the concept of individualized education has been put into the national education plan, and the way to promote Chinese education has been pointed out from the macro level, that is, individualized education. "Adaptive" refers to the nature and personality of students. The core of adaptive education is "pursuing education suitable for students' development". According to different learners' own differences, it implements the best learning behaviors or educational activities. From this point of view, adaptive education is "personalized education" and "humanistic education" [2].

There are many educators in history who have similar educational ideas to "adaptive education". For example, 
Confucius, a famous educator in ancient China, put forward "teaching students according to their aptitude"; Taoism advocates conforming to human nature; Wang shouren, a master of mind learning, advocated that education should be "guided by temperament"; Rousseau, a French educator, believed that education must respect the nature of children; American educator Gardner put forward that education should pay attention to the development of students' multiple intelligences and so on.

“Adaptive education” mainly includes three aspects: Firstly, teachers should respect the individual differences of students, and understand that each student has his or her own shining point. In various learning situations, they will have different feelings and gains. Secondly, teachers should respect students' subjectivity and play the role of guide, then all the links of education should revolve around students' ability and interest. Thirdly, one should not be less, while emphasizing personality development, it should also promote collective progress[3].

\section{B. History and application of positive psychology}

Positive psychology is a field of psychological research that emerged in the United States in the 1990s. Positive psychologists such as Seligman and Kaliman advocate that psychology should start from the inherent and potential constructive power of human beings as well as virtue and kindness, and use a positive attitude to interpret various psychological problems of human beings, to stimulate the positive psychological quality of human beings, and to help people develop their potentials to an infinite extent and achieve better results[4]. One of the important theoretical sources of positive psychological education is the rise of positive psychology. The trend of thought of positive psychological education has an important impact on the theory and practice of contemporary mental health education in China. The concept and technology of positive psychology are widely used in the field of mental health education[5].

\section{The significance of adaptive education}

For children, adaptive education will be conducive to the cultivation of their interest, so that they can develop in the direction of their own interest, which can reduce the occurrence of "hollow disease", and then their life goals will be clearer and they will be more likely to lead a more meaningful life. For teachers, in the process of adaptive education, they will have a better understanding of children and the relationship between teachers and students will be more harmonious. On the other hand, teachers will also know themselves better and get a lot of inspiration from children, at last they will continue to grow and surpass themselves. For traditional Chinese parents, in addition to growing up with their children, children's happiness will also increase their own happiness, and the psychological distance between parents and children will be closer. As for the society, social responsibilities will be more likely to be assumed by children who grow up healthily and happily, incidence of mental illness will decrease, social resources will be more economical and the society will develop better and faster.

\section{Practical application of adaptive education}

Up to now, more and more Chinese schools are practicing "adaptive education”. For example, Taixing experimental junior high school education group, based on the actual situation in the region and in their school, has explored an effective way of quality education called adaptive education[6]. The school has made great efforts to create a campus culture that advocates delicacy, devotes itself to kindness and pursues excellence. Then they have put forward and implemented good-hearted education focusing on material and sincerity according to local conditions. Han Jin, as the principal of Shenlong Primary School in Wuhan, Hubei Province, led the teachers and students to fully explore the educational implication of "automobile culture" and its relevance to education, to explore how to penetrate the essence of "automobile culture" into all aspects of school education and teaching, to promote the all-round development of teachers, students and the school. The organic combination of car culture and school work forms the school characteristic culture of "seeing culture by car, educating people by culture, educating people by car”[7].

\section{EXISTING PROBLEMS IN ADAPTIVE EDUCATION}

Many schools, especially primary and secondary schools have carried out "adaptive education" on the basis of the original educational guidelines of their own schools. For example, in order to cultivate children's interests, they have hold various interest classes, in which children can choose different interest classes according to their own interests and their own conditions. The curriculum is also arranged according to the characteristics of children. These changes have been not only in the software, but also in the school environment and teaching facilities. As mentioned before, the significance of "adaptive education" is very important, but due to the impact of the social environment and other reasons, most schools still focus on "examination-oriented education", and the evaluation on students (especially primary school students), is still based on the merits and demerits of academic performance.

When "adaptive education" meets "exam-oriented education", we have to compromise. In reality, when "exam-oriented education" occupies a dominant position, school teachers and parents tend to forget "protecting children's nature”, "respecting children's wishes" and so on. At present, the so-called "adaptive education" has not been really implemented for a long time in China.

\section{ANALYSIS OF THE REASONS FOR THE FAILURE TO IMPLEMENT ADAPTIVE EDUCATION}

\section{A. The results of adaptive education are not fully adapted to the needs of the society}

Although adaptive education comes into being on the basis of the needs of social development, the real adaptive education may not fully meet the needs and the expectations of society. The development of society needs talents from all walks of life. To meet the needs of society, vocational training and education must be carried out, which is contradictory to the view of “adaptive education”. The professions that children want to engage in may not be able to meet the needs of talents in society. Therefore, "adaptive education” is difficult to be really carried out if we want to meet the needs of current social development. 


\section{B. The great pressure brought by social comparison}

Modern society is a fiercely competitive society. In schools, the performance of teachers will be compared with each other. In families, the academic performance of children will be compared with other children's. In such an environment, teachers and parents are facing great psychological pressure, and children's unsatisfactory academic performance is the trigger. And the most effective way to improve academic performance is "exam-oriented education". For parents and teachers, it is easy to cultivate along with the needs of society and the temptations of society, in a sense, they do not need to think too much in the process.

At this time, if parents and teachers still decide and always adhere to the "adaptive education" mode, they must be determined and can't be affected by the social trend, which is a great psychological challenge.

\section{Uncertainty in adaptive education}

In the process of adaptive education, children may experience confusion on the way to explore their true selves. During this period, parents and teachers will be very anxious. In order to eliminate the fear of the unknown, they will terminate the so-called "adaptive education" and persuade their children. Then they will design life path for their children according to their own life experience. Once the children's future is "visible", parents will be relieved. The uncertainty of adaptive education is also reflected in the fact that there is no uniform standard to measure the success of adaptive education, so adaptive education is hard to be convinced.

\section{The defects in adaptive education}

Although "adaptive education" has many advantages, it only takes into account the discovery and cultivation of students' best potential, ignoring other factors in the process of education, such as the failure of teaching due to the lack of consideration of appropriate amount and timing[8]. In order to make up for the defects of adaptive education, He Futian, an education expert in Taiwan, has put forward the concept of “Three Suitable Serial Education" for children's education. However, the individual differences of students make it difficult for teachers to grasp the suitability, appropriate amount and timely education at the same time.

\section{EXPLORATION ON THE APPLICATION OF POSITIVE PSYCHOLOGY IN ADAPTIVE EDUCATION}

\section{A. Paying attention to infiltrating the cultivation of positive psychological qualities into the adaptive education}

The ultimate goal of education is to make every child become a better version of him and find the value and meaning of his own life. As a way of individualized education, adaptive education is one of the ways to achieve this goal. However, adaptive education has many shortcomings. At present, examination-oriented education is still the main education in primary and secondary schools in China.

Seligman's graduate student, Alejandro Adler, has done a lot of research in different schools. For example, one of his studies was in 18 schools. Eleven schools (5,347 students) were treatment schools and seven schools (3,138 students) were the controls. The principals and teachers from both groups of schools were told that they were being trained to teach the GNH curriculum. The students in both groups of schools received the same number of classroom hours during the real 15-month Life Skills Course and the placebo 15-month course: 2 hours per week. All principals and teachers in the 11 treatment schools received training during a 10-day GNH curriculum retreat. Teachers learned to infuse their academic subjects (e.g. math, science, and reading) with the life skills. Literature, for instance, was taught through a GNH lens by identifying strengths and virtues in characters from novels and by encouraging students to use these strengths in their daily lives. The principals and teachers from the seven schools in the control group received training during a 4-day placebo GNH curriculum retreat, during which they learned about how to teach nutrition, psychology, and human anatomy. At last, they found well-being rose and was significantly higher in students in the treated schools than in those in the placebo schools. Most importantly, academic achievement measured by the national exams, rose dramatically and remained much higher in the treated schools. They also found that more student engagement and more perseverance accounted for most of the superiority in examination results.[9]

Adaptive education does not fully conform to children's nature and allow them to be free and scattered, but allows them to explore themselves more and see what they really want and what they are really interested in. This is different from exam-oriented education. In this process, we can instill some skills and positive psychological qualities into them through classroom teaching, encourage them to form their own independent personality and independent thinking, and eventually let them become themselves, a real person.

\section{B. Promoting the construction of suitable curriculum in schools}

Curriculum reform is the key to the development of school connotation. The idea of top-level design of a school must be related to teachers and students through curriculum. Therefore, the curriculum determines the form of the school and embodies the culture of the school. The curriculum content is the core guarantee of the quality of education and teaching in a school, and the suitable curriculum is the value presentation of the adaptive education. Curriculum construction itself is a long and complicated project, and each school needs to construct its own characteristic suitable curriculum according to its own condition, which is even more difficult. In the process of construction, it should be guaranteed and supported by policies. Therefore, firstly, it is urgent to establish a sound curriculum construction system. Secondly, efforts should be made to improve the curriculum leadership of principals and teachers to maximize the development opportunities. Thirdly, we should seek the support of all sectors of society to reserve space for the development of school curriculum construction. [10]

Adaptive education and positive psychology are both influenced by humanism to some extent, and have many common points. In the construction of adaptive curriculum, we should absorb the essence of positive psychology and make up for adaptive curriculums' shortcomings, so as to promote the popularization and application of adaptive education. 


\section{Establishing a positive evaluation system}

Positive psychology attaches great importance to the influence and decisive role of social and cultural environment on mental health, personality, creativity, individual emotions and psychotherapy. Positive organizational systems include positive small systems and positive large systems. Positive small systems include well-connected communities, effective schools, the media that have social responsibility, healthy families and so on; the positive big systems include citizens who have sense of responsibility as well as professional ethics, etc[5]. In order to truly carry out adaptive education, we need to establish a positive organizational system. First of all, we need to establish a positive evaluation system, which includes the social evaluation on the quality of the schools, the schools' evaluation on the teaching level of the teachers, the teachers' evaluation on whether the students are excellent or not and so on. In this system, we should not only refer to the students' academic achievements, but also examine individual psychological quality, emotional stability and other indicators. In addition to achieving the rationalization of evaluation content, we should also achieve: humanization of evaluation objectives, diversification of evaluation subjects and diversification of evaluation methods [11]

\section{Promoting the co-growth of parents and children}

As we all know, parents are children's first teachers. A large proportion of parents who grew up in traditional Chinese families may not have "self" in the process of their growth, but just drift with the tide and gradually become parents like their own parents. When children are young, they worry about their children. When their children grow up and get married, they worry about their children's children. From a certain point of view, parents from generation to generation have trained excellent successors and made great contribution to the development of the society. However, from the perspective of education, such parents can't really achieve "adaptive education". They will follow the rules, the needs and expectations of the society to raise their children. Therefore, parents should learn how to be themselves and grow up together with their children. When parents experience more positive emotions and recognize the significance of this practice, they will naturally stick to "adaptive education”. This process requires the participation of teachers, parents and children, and is based on the positive evaluation system has been improved, so it has a long way to go.

\section{CONCLUSION}

Different people have different views on education. But the real education should be "people-oriented", which is similar to the educational concept of "adaptive education", and positive psychology is derived from the influence of humanistic psychology. It can be seen that there are many similarities between positive psychology and adaptive education. Adaptive education is the requirement of social development, but for various reasons, it has not been really implemented. In the process of implementing adaptive education, we should take some measures to overcome the difficulties and help adaptive education move forward, such as paying attention to infiltrating the cultivation of positive psychological qualities into the adaptive education, promoting the construction of suitable curriculum in schools, establishing a positive evaluation system and promoting the co-growth of parents and children.

\section{REFERENCES}

[1] Xu Kaiwen. Interpretation of "Hollow Disease" in the Era [J].Shanxi Education: Comprehensive Edition, 2016,9(11): 58-60.(In Chinese)

[2] Guo Ran, Sun Yu. Research on the Practical Application of Adaptive Education [J]. The Way to Success, 2017 (10): 2-3.(In Chinese)

[3] Gu Penglei. Practice and thinking of "adaptive education" based on quality education [J]. The Way to Success, 2019 (18): 22.(In Chinese)

[4] Kuang Zhihua, Ye Haosheng. Three New Orientations of Contemporary Western Psychology and Their Comparison [J]. Journal of Psychology, 2005 (05): 702-709.(In Chinese)

[5] Wang Yan. A ten-year review of positive psychology[J]. Journal of Henan Institute of Education (Natural Science Edition), 2014, 23 (03): 27-31.(In Chinese)

[6] Pan Yusheng. Practice and Reflection on "Adaptive Education" for quality-oriented Education [J]. Jiangsu Education Research, 2018 (29): 32-34.(In Chinese)

[7] Han Jin. Shenlong Primary School: Creating a brand of adaptive education featuring "automobile culture" $[\mathrm{J}]$. Information Technology Education in Primary and Secondary Schools, 2018 (06): 17-20.(In Chinese)

[8] He Futian. Children's Education View of three suitable continuous education [A]. Anhui Basic Education Research (No.3, 2015)[C]. Anhui Basic Education Reform and Development Co-innovation Center, 2015:6.(In Chinese)

[9] Martin E.P. Seligman. Positive Psychology: A Personal History [J]. Annu. Rev. Clin. Psychol. 2019.15:3.1-3.23

[10] Gao Chonghui. Practice of School Adaptive Curriculum System Construction from the Perspective of Characteristic School Construction [J]. Modern Education Science, 2018 (07): 152-156.(In Chinese)

[11] Sheng Fuping. Evaluation Innovation Based on “Adaptive Education”[J]. Chinese Moral Education, 2014 (13): 52-53.(In Chinese) 